\title{
LOS ORIGENES DEL PRIMER FEMINISMO Y EL CONGRESO FEMENINO NACIONAL DE MALLORCA (1869-1883) ${ }^{1}$
}

\author{
Isabel Peñarrubia \\ Doctora por la Universidad de Barcelona
}

\section{RESUMEN}

Se estudia el primer feminismo en Mallorca a partir de los preparativos de un Congreso Nacional Femenino que se había de celebrar en Palma en 1883, ligado al obrerismo republicano y a los contactos con un pionero feminismo en el resto de España. Los orígenes del movimiento se remontan al Sexenio Democrático cuando las dirigentes feministas se encuadraban en las filas del internacionalismo y del republicanismo. El contexto que posibilitó aquella organización hay que buscarlo en la Palma industrial y comercial de la segunda mitad del XIX. La ofensiva del conservadurismo y de la iglesia explicaría el repliegue del movimiento.

Palabras clave: Feminismo, librepensamiento, anarquismo, obrerismo republicano

\section{ABSTRACT}

Feminism was studied for the first time in Majorca from the preparations of a National feminine Congress that had to take place in Palma in 1883, and that was related to the republican working-class movement and the contacts with a pioneer feminism in the rest of Spain. The origins of that movement go back to the Democratic Six year- period, when the feminist leaders belonged to the internationalism and republicanism ranks. We must search for the context that made possible that organization in the industrial and commercial Palma of the second half of the 19th century. The offensive of conservatism and the Church explains the withdrawal of the movement.

Key words: feminism, freethinking, anarquism, republican working-class movement

\footnotetext{
${ }^{1}$ Este articulo resume el libro de la autora Entre la ploma i la tribuna. Els orígens del primer feminisme a Mallorca (18691890), Abadia de Montserrat i Institut Català de la Dona, Barcelona 2006.
} 


\section{La razón oculta del Ángel del hogar}

La construcción del género fue extremadamente eficiente durante la etapa isabelina ${ }^{2}$. El Sexenio Democrático supuso un paréntesis que vio tambalearse muchas de las viejas ideas. En aquel periodo se vivió una eclosión del asociacionismo y de la actividad política popular, lo que propició que las mujeres ocuparan la palestra y la calle. Pero el conservadurismo de la Restauración volvió a tejer la identidad femenina doméstica, oponiéndola al ansia de "yo" y de libertad románticas. La reclusión de la mujer en el hogar fue idealizada y adornada con tintes románticos, vendiéndose como el destino heroico del Ángel del hogar ${ }^{3}$. Precepto que debía cumplir toda mujer que no quisiera ser tratada de marisabidilla egoísta, es decir, de degenerada. Se había ido construyendo una indiferenciada naturaleza femenina, abocada irremisiblemente a servir al hombre y a la maternidad. Era la división y especialización de géneros, creados por el patriarcado en la contemporaneidad. Porque la entrada en el ámbito público de una nueva clase, la burguesía, con el advenimiento del capitalismo y del régimen liberal, había especializado a sus hombres en los negocios y en la política. La familia dejó de ser una unidad de producción, situación que se había prolongado durante toda la época gremial. A partir de entonces se vivió la mayor separación entre espacio público y espacio privado. Este último fue atribuido a la mujer que quedaba exclusivamente dedicada a ser el Ángel del hogar. Se enaltecía su papel de descanso del guerrero, que debía hallar un bálsamo cuando volvía cansado de la lucha y de la competencia exterior.

Los talleres externos y las fábricas fueron sustituyendo a los talleres familiares en donde antes trabajaban las mujeres. Así y todo, cono no se podía negar la realidad del trabajo fabril de la obrera, la ideología patriarcal lo consideraba como una desgracia necesaria. Por tanto los varones proletarios luchaban para que se acabara y poder tener esposas que fueran sus propios ángeles hogareños. La educación de los hijos y la casa ostentosa y confortable eran muy importantes para la burguesía como símbolo de estatus. Ello requería la dedicación exclusiva de la esposa que ejercía una especie de sacerdocio doméstico. Se había de preservar a aquél ángel, a aquella sacerdotisa desde que era niña y que fuera tutelada por el padre o por el marido, defendiéndola de los avatares del espacio público. De esta forma el hombre escamoteaba a la mujer el acceso a la propiedad, a las profesiones liberales, a los estudios secundarios y universitarios, a la política y a la palabra pública. A las mujeres se las convertía en menores de edad y se las apartaba de todo lo que confería individualidad y poder, después de que filósofos y científicos hubieran dictaminado su presunta debilidad ${ }^{4}$.

\section{Un destino condicionado por el analfabetismo y la educación de adorno}

Durante los años sesenta del siglo XIX y desde las aulas del Ateneo Balear surgen las primeras inquietudes y iniciativas burguesas para paliar la incultura y la reclusión doméstica femenina. Aquellas propuestas culminaron en la krausista Escuela Mercantil de Palma, fundada en 1880 como centro coeducativo y de formación profesional para la mujer. Tanto aquella iniciativa, como las conferencias del Ateneo, como los escritos de los periódicos republicanos coincidían en plantear que la instrucción era el primer paso hacia la redención femenina. Pero el feminismo de los años ochenta no fue improvisado ya que sus raíces arrancan del Sexenio Democrático. La reivindicación feminista de los años 80 sería deudora, por una parte, de la

${ }^{2}$ Véase de SÁNCHEZ LLAMA, Iñigo Galería de escritoras isabelinas. La prensa periódica entre 1833 y 1895 , Feminismos. Cátedra, Madrid 2000.

${ }^{3}$ KIRPATRICK, Susan, Introducción a Antología poética de escritoras del siglo XIX, Edit. Castalia. Instituto de la Mujer, Madrid, 1992, pp. 12-13.

${ }^{4}$ VALCÁRCEL, Amelia La política de las mujeres, Feminismos, Ediciones Cátedra, Madrid 1998. 
praxis y del nivel de análisis alcanzados por las modistas internacionalistas de La Virtud Social y, por otra, de las jóvenes republicanas federales. Todas ellas presentes en el espacio público como oradoras en mítines, articulistas de prensa y participando en manifestaciones.

En la Mallorca del último tercio del XIX se vivió, como en el resto de España, la demanda de mejorar la educación femenina. Pero ello no suponía que el acceso de la mujer a la cultura se contemplara en función de desarrollar su personalidad per se, sino como un instrumento de regeneración social. Se trataba de educar a madres que educarían a futuros hombres. La formación de la mujer preocupaba a la Iglesia que la veía como un medio de recristianizar a la familia y, por tanto, a la sociedad. La mujer era la transmisora de unos valores conservadores que la Iglesia utilizaba para que perdurase su hegemonía social. Siguiendo con el discurso dominante, la responsabilidad de la moralidad social era de la mujer y se la hacía culpable de la inmoralidad masculina. Como habían denunciado las primeras feministas, ligadas a la Primera Internacional y al republicanismo mallorquín, la mujer tenía todos los deberes sociales sin tener ningún derecho. Era la antigua vindicación de Mary Wollstoncraft: si la población femenina era adulta para cumplir la ley también lo tenía que ser para hacerla, si subía al cadalso era plausible que lo hiciera a la tribuna.

Respecto a Mallorca, y dejando para más adelante la situación de la obrera, interesa poner de relieve las nulas salidas profesionales que tenían las jóvenes de origen burgués, a quien se le vetaba el ejercicio de las profesiones liberales. De todas formas, el principal escollo era la falta de instrucción ya que a la Mallorca del 1887 el índice femenino de analfabetismo era del $88^{\prime} 05 \%$ mientras que el masculino era del $73^{\prime} 65 \%$. La sociedad patriarcal relegaba a las mujeres al espacio doméstico y al trabajo descualificado. Los estudios femeninos eran acaparados por los colegios religiosos y se reducían a los estudios de adorno. La minoritaria educación popular pasaba por las costuras de las monjas o bien por la escuela pública. La enseñanza femenina estaba marcada por la dudosa preparación de las maestras y por la presión pragmática de los padres.

\section{El Ateneo Balear abre sus puertas a las mujeres}

No deja de sorprender la contribución de las literatas mallorquinas al movimiento de la Renaixença a pesar de tan desfavorables circunstancias. Se trata de figuras literarias todavía poco conocidas o poco valoradas porque a menudo se les aplica un rasero de cualidad mucho más restrictivo que a sus compañeros masculinos. Consideramos que, de entre todas las artes, el cultivo de la literatura sería el más compatible con la situación de aislamiento y de falta de estudios que sufrían las mujeres. Un oficio que se podía practicar en casa y que admitía el autodidactismo. De todas maneras surge el interrogante sobre de donde sacarían aquellas escritoras la formación necesaria para expresar lo que sentían. Todas ellas provenían de familias burguesas que podían pagar estudios universitarios a los hijos. Pero mientras sus hermanos partían a estudiar a Barcelona y a Madrid, ellas se habían de contentar con la escolarización básica y ésta duraba con mucha suerte hasta los 15 años. La respuesta a este interrogante sería que las escritoras desde niñas eran grandes lectoras y habían comenzado a escribir muy pronto.

Creemos importante indagar el ambiente socioeconómico que posibilitó el nacimiento de aquella generación de literatas y que pudieran continuar con su actividad a pesar de los escollos que encontraron. Respecto a las poetisas que se han podido documentar vemos que vieron la luz en hogares de comerciantes o intelectuales, hijas de burgueses que protagonizaron la modernización económica y cultural isleña. O por nacimiento o por matrimonio pertenecían a la burguesía liberal de Palma. Creemos que ello debió de facilitar al menos la comprensión de sus aspiraciones literarias.

Las poetas frecuentaban el Ateneo Balear, sociedad de influencia krausista que defendía la promoción de la mujer mediante su acceso a la instrucción. Así en 1868 en el ateneo se discutía sobre los defectos que arrastraba la enseñanza femenina. Al año siguiente aquella sociedad dio un gran paso en el reconocimiento de la igualdad de derechos de las mujeres cuando 
el presidente de la Sección de Literatura e Historia invitó a las señoras no sólo a enviar sus composiciones, sino también a asistir a las sesiones. Se trataba del poeta Pons y Gallarza quien calificaba la iniciativa de revolución pacífica, por lo que tenía de subversivo contra la costumbre de alejar a la mujer del trato social, científico y literario. Y efectivamente en aquél mismo año el Ateneo organizó lecturas poéticas a las que asistía un nutrido público femenino. Allá leyeron sus poemas las escritoras Angelina Martínez, Margalida Caimari, Joana María Ginard y Manuela de los Herreros junto a otros poetas y al propio Zorrilla, entonces de visita en la isla.

Por otra parte, se ha de puntualizar que las poetas románticas fueron mujeres de origen burgués muy bien adaptadas al estereotipo femenino. Aquel modelo las hacía socialmente conservadoras y muy religiosas, por tanto, apartadas del modelo coetáneo de la mujer republicana $\mathrm{u}$ obrerista. Las escritoras en ningún momento abogaron por los derechos civiles $\mathrm{o}$ políticos de la mujer. El hecho de escribir, publicar en las revistas de la época, participar en certámenes literarios, en recitales de poesía o ejercer beneficencia en organismos públicos no cambió su estatus de mujer doméstica. En ningún momento se plantearon acabar con el orden familiar que pesaba sobre la mujer. En este sentido, su actuación no pasó de un reformismo católico que se concretaría, en el caso de Caimari y de los Herreros, en luchar contra la prostitución, en extender la enseñanza a niñas y a adultas obreras o en fundar guarderías confesionales para las madres trabajadoras. Por ello, cuando el 1883 las feministas de la Unión Obrera Balear convocaron a las escritoras mallorquinas para que se adhirieran al Congreso Nacional Femenino, ellas se mantuvieron al margen. No respondieron, aunque las organizadoras del congreso solo les pidieran su contribución a un álbum poético. Fue inútil que las mujeres de la Unión Obrera Balear, para no suscitar el rechazo clerical, no hablaran de laicidad ni de vinculación con la disidencia política. Fue suficiente el grito de orden emitido por la Iglesia, ante un movimiento que no surgía de sus filas, para que las poetas ignoraran la invitación a colaborar en el futuro congreso.

\section{ciudadanía}

1868-1873: la mujer aprovecha la democratización y comienza a ejercer la

La modernidad era ya imparable y con ella la salida de las mujeres al ámbito público, después de su inmemorable reclusión en la privacidad. Las nuevas libertades que trajo el Sexenio Democrático propiciaron la participación de la mujer en la vida política. Así vemos a líderes de filiación republicana, como Mina Puccinelli, Consuelo Aragón, la ciudadana Albons y Magdalena Bonet, publicando artículos y dando mítines. Esta última hizo discursos que fueron ensalzados por la prensa republicana menorquina y peninsular. Mujeres republicanas impartieron clases nocturnas para obreras. Por otra parte, un grupo de modistas ligadas a la Primera Internacional organizaron la sociedad La Virtud Social, que desde el primer momento articuló un discurso de liberación de la mujer contra la doble opresión que padecía: en la economía capitalista y en la familia. Esta dinámica resurgió en los años 80 cuando un gobierno liberal facilitó el nacimiento de una organización femenina dentro de la Unión Obrera Balear, gracias a la nueva ley de asociaciones y a una mayor libertad.

Escritores y diarios conservadores alzaron su voz en contra de estos primeros pasos en la emancipación femenina. Su denuncia nos sirve de testigo de hasta que punto se había extendido la oleada feminista. En efecto, las mujeres empezaban a manifestar su pensamiento en público y sin complejos. Ese fue el caso de una joven librepensadora, alumna de un colegio privado de señoritas, del que había sido expulsada por discrepar de la maestra, en base a argumentos racionalistas. En febrero de 1870 aquella alumna contestataria se convertía en la heroína de la prensa republicana mientras era criminalizada desde diferentes púlpitos. También será una constante la participación femenina en manifestaciones republicanas y obreras en la calle. Ellas se movilizaron masivamente contra la recluta de sus hijos, hermanos y maridos o por la República Federal o en honor de los Agermanados. Por primera vez la prensa republicana resaltó 
su presencia, manifestándose en la calle y bordando banderas y estandartes disidentes o estampando sus firmas en pliegos reivindicativos.

El republicanismo tuvo, durante aquél paréntesis de seis años de democracia, una especial preocupación por la enseñanza de la mujer. Se solía relacionar la instrucción de la mujer con su rescate de la órbita del integrismo religioso. El periódico La Bocina alegaba el 22-X-1871 que por el simple hecho de que las féminas supieran leer el Evangelio podrían verse libres de las interpretaciones sesgadas y reaccionarias de los curas. Argumentaba que si las mujeres de las clases populares intentaban aprender a leer y a escribir eran condenadas de por vida por la Iglesia. Y mucho peor si se proponían tener estudios superiores. Como es sabido, cada matrícula femenina en un instituto o en la universidad, suponía unos trámites burocráticos de solicitudes de permisos y graciosas concesiones de la autoridad pertinente. El Real Decreto del 16-III-1886 prohibía a la mujer seguir estudios universitarios. Hasta el 1910 no se abrieron del todo las puertas de los institutos y universidades a las mujeres, reconociendo sus títulos académicos de forma oficial. Pero las escuelas laicas se multiplicaban y hacían esfuerzos por atraer no sólo a las niñas en edad escolar si no también a las adultas. La prensa republicana comentaba con orgullo que más de cien ciudadanas asistían cada noche a las clases impartidas en el Casino Republicano de Palma. También la Escuela Democrática impartía clases a mujeres y las convocaba a reuniones políticas. Se publicaban noticias de que en muchos pueblos los republicanos abrían escuelas masculinas y femeninas.

\section{Las obreras bakuninistas de la AIT contra el patrón y el pater familiae}

Las trabajadoras se ocupaban en los sectores industriales típicamente femeninos. Que en la Mallorca del XIX se concretaban en el calzado, el textil, las industrias agroalimentarias, las fábricas de cerillas, los bordados y los bolsos de plata. Estas industrias basaban su competitividad en los bajos costes laborales y por ello empleaban a una gran parte de mano de obra femenina. La ideología patriarcal propiciaba los bajos salarios de la mujer, depreciando su trabajo como circunstancial y siempre subsidiario del masculino. Las condiciones laborales de las mujeres fueron todavía peores que las de los hombres, caracterizándose por jornadas laborales agotadoras, falta de higiene, ausencia de seguridad, manipulación de substancias tóxicas, en una palabra unas duras condiciones en el trabajo, comunes tanto a talleres como a fábricas más mecanizadas. Las obreras por su condición de mujeres soportaban no sólo la discriminación salarial sino además un trato humillante por parte de capataces y amos. Eran constantes el acoso y los abusos sexuales en el lugar de trabajo y en el recorrido diario entre éste y el hogar. Estos atropellos fueron continuamente denunciados por las mujeres más activas del movimiento obrero.

La importante presencia de la mano de obra femenina en la industria explicaría la temprana respuesta obrera. Las primeras trabajadoras organizadas denunciaron la situación del trabajo femenino pero también la explotación y humillación que padecían como mujeres, en la calle y en la familia. El 7-II-1870 se organizó en Palma una asociación de costureras, La Virtud Social, adherida al Centro Federal de Sociedades Obreras de Palma, que formaba parte de la Asociación Internacional de Trabajadores. Este precoz movimiento obrero nació del contacto con su homónimo de Barcelona, que tenían como órgano de expresión La Federación. La Virtud Social en el momento de su fundación estaba compuesta por 56 modistas. Y ya en junio el numero de afiliadas había aumentado a 71. El Centro Federal de Sociedades Obreras de Palma en abril del 1870 convocó un plebiscito para decidir donde se celebraría el primer congreso obrero español y las 56 obreras federadas votaron aquella cuestión. Sería un hecho relevante el hallar una asociación mixta donde por primera vez las mujeres compartían reivindicaciones y local en pié de igualdad con los varones y que además tenían derecho a voto y a representación en puestos de decisión, como el consejo local de la federación de Palma. En dicho consejo, el mismo día de la fundación de la sociedad de modistas, habían sido elegidas tres delegadas de entre ellas. 
El semanario internacionalista El Obrero, que se publicaba en Palma, reproducía en marzo de 1870 el manifiesto de adhesión de La Virtud Social al Centro Federal. Allá se analizaba la explotación padecida por la mujer a lo largo de los siglos, demostrando que las autoras tenían un considerable conocimiento histórico. Empezaban exponiendo como en la antigüedad los hombres habían considerado a las mujeres sus esclavas. Atribuían una misión liberadora al primer cristianismo, con sus proclamas igualitarias, compartiendo así el imaginario de otros movimientos heterodoxos como el socialismo utópico, el espiritismo, la masonería y el librepensamiento en general. Pero la situación subalterna de la mujer se había vuelto a consolidar durante el feudalismo y incluso en plena Revolución Francesa. Las autoras pasaban del análisis del pasado al del presente cuando afirmaban que los gobiernos burgueses seguían sin reconocer los derechos de la mujer. Pero ahora las oprimidas contaban con un poderoso instrumento de liberación: la Asociación Internacional de Trabajadores. El manifiesto de La Virtud Social es la primera proclama feminista mallorquina que conocemos y, seguramente, una de las pioneras a nivel español. Aquellas obreras habían puesto a la mujer como sujeto histórico y así en cada período histórico habían analizado su situación.

Al poco tiempo las internacionalistas mallorquinas habían establecido contactos con sus homónimas madrileñas, identificándose todas ellas con los postulados de emancipación femenina. Las modistas isleñas también entraron en relación con las internacionalistas catalanas de La Federación, publicando El Obrero del 12-VIII-1870 una carta de la dirigente bakuninista de Barcelona Elisa Huigon. Se trataba de una propuesta de coordinarse con sus compañeras mallorquinas a las que consideraba adalides de la emancipación femenina. Elisa sostenía que los pilares sobre los que se aguantaba la esclavitud de la mujer eran el fanatismo religioso y el bochornoso e insignificante papel que desempeña en el seno de la familia, de cuyo jefe es la primera en sufrir las consecuencias de su suerte adversa y de su mal trato, ya que el marido pocas veces trataba a la esposa como a una compañera con quien compartir las cosas agradables de la vida. Elisa Huigon participaba del mismo análisis feminista que sus afines de Mallorca y de Madrid cuando señalaba el estatus subalterno de la mujer como la principal causa de postración femenina. No absolvía a los maridos proletarios ya que ellos participaban de la jerarquía sexista. Ella apuntaba hacia otro pilar de la exclusión femenina: la falsa naturaleza atribuida a la mujer por la religión y los prejuicios sociales.

Aunque las asociadas a La Virtud Social eran modistas, en sus manifiestos se dirigían a todas las obreras. El manifiesto del 26-V-1870, por ejemplo, lo destinaban a sus compañeras de infortunio. En él se aludía a la mala situación de las obreras fabriles que empezaban a trabajar desde niñas y siempre sujetas al frenético ritmo de las máquinas. Aquella arenga intentaba animar a las trabajadoras a que asistieran a las reuniones que la sociedad de modistas hacía, todos los viernes a las 20 horas. Del discurso de la proclama se desprendía la autoría femenina, ya que vindicaba el derecho de la mujer al trabajo, ante la creciente competencia masculina en todos los oficios. Las modistas asociadas adoptaban una posición contraria a la recurrente reivindicación de los obreros de que no trabajaran sus mujeres. Aquellas obreras de la aguja se quejaban de los bajos salarios, siempre inferiores a los masculinos, enfatizando que ello les hacía depender de la familia. Continuaban argumentando que las obreras, aunque sin instrucción por culpa de aquella sociedad explotadora, tenían que demostrar que conocían sus derechos y que por ello se organizaban.

Las denuncias que hizo aquel grupo de modistas de la subalternalidad femenina ocuparon mucho más espacio en sus discursos y manifiestos que las reivindicaciones estrictamente laborales. En este sentido también se ha de comentar la arenga que en junio de 1870 dirigían des de las páginas de El Obrero a sus maridos, hermanos e hijos. Iba destinada a conseguir la solidaridad de sus compañeros y por ello comenzaba describiendo la desgraciada situación de la mujer trabajadora. Ellas abundaban en una idea clave de la AIT, que adaptaban a la realidad femenina: no más deberes sin derechos. Insistían en la idea de que sin poseer ningún derecho estaban cargadas de deberes. Relacionaban la falta de autonomía que padecían las obreras con sus bajos salarios, considerados complemento de los masculinos. Además las modistas a lo largo 
del manifiesto aludían a la escasa libertad de movimiento de la mujer. Porque necesitaba el permiso del marido, padre o hermano, -como si fuera una eterna menor de edad, -para asistir a las reuniones que la asociación de obreras celebraba en el local de la federación. Acababa exhortando a los compañeros a romper con las antiguas costumbres, que legitimaban a los varones de la familia a controlar a los elementos femeninos como defensores de la honra de la casa.

\section{Magdalena Bonet, una líder republicana que transcendió el marco isleño}

Los republicanos se proponían que las mujeres participasen en la actividad política. Por ello intentaban que se encuadrasen en sus organizaciones, casinos, sociedades mutualistas y recreativas y que asistieran a sus escuelas, saliendo al espacio público. Así vemos que durante el Sexenio muchas mujeres participaron en las manifestaciones, estamparon sus firmas contra el esclavismo y otras causas, promovieron actos públicos y hicieron mítines contra las quintas y escribieron artículos en la prensa etc. Éste era el ambiente que en 1870 respiraba Magdalena Bonet, una adolescente de 16 años en plena formación. Ella y sus compañeras vivieron aquella ansia de revisar los valores de la sociedad isabelina, en una edad tan configuradora de la personalidad como sería entre los 16 y los 20 años. La libertad política que trajo la Gloriosa propició un criticismo en determinados ambientes que iba desde la secularización de la vida hasta el abandono del precepto del Ángel del hogar. Además, por primera vez, la sociedad valoraba las opiniones y la participación en la vida política de adolescentes. Prueba de ello eran los mítines en centros republicanos a cargo de jóvenes y hasta de una niña de ocho años de Palma. Este encuadramiento de niños y muchachos de ambos sexos en las filas republicanas iba acompañado de la asistencia a las numerosas escuelas creadas por el partido. Enmarcado en esta dinámica no ha de extrañar que en el Auxilio Federal, asociación mutualista de la que Magdalena formaba parte en 1873, se admitieran socios de ambos sexos a partir de los 15 años. Disposición que se ha de relacionar con las nuevas libertades pero también con el hecho de la abundancia del trabajo infantil en fábricas y talleres.

Esta generación de muchachas, formadas durante un sexenio pletórico de libertad, dio su fruto en 1882 cuando ya contaban unos treinta años. Ellas aprovecharon la primera liberalización en el asociacionismo durante la Restauración, -introducida por el gobierno Sagasta, -para organizar ahora ya un verdadero movimiento feminista, que tenía que culminar en el Congreso Femenino Nacional. Pero mientras tanto es interesante seguir los discursos de Magdalena Bonet para analizar la evolución de su pensamiento y las influencias que recibió. La precoz líder republicana dio numerosos mítines, a lo largo del Sexenio, sobre el matrimonio civil, la separación de Iglesia y Estado y la coyuntura política española e internacional. Estos parlamentos, reproducidos por la prensa republicana mallorquina, dejan entrever a una elocuente oradora dotada de una buena formación política, a pesar de su juventud, y además, bien informada de la situación política europea. Estas condiciones hicieron que se convirtiera en un símbolo de la nueva mujer progresista para el republicanismo español. Por ello la prensa republicana de diferentes ciudades de España reproducía y alababa sus discursos.

En una primera etapa, enmarcada en el Sexenio Democrático, las ideas de Magdalena Bonet fueron todavía deudoras de las de los dirigentes republicanos de su entorno, quienes tanto si se trataba de mujeres como de hombres sólo empezaban a vislumbrar la incorporación de la mujer a la nueva cultura heterodoxa. Había surgido la necesidad de liberar a la mujer del confesionario y de que pudiera ocupar la calle, tan activa entonces. Tanto Magdalena como sus amigas, la zaragozana Modesta Periu y la italiana Mina Puccinelli, llamaron a las mujeres a manifestarse e incluso a coger las armas, demostrando que las féminas poseían virtudes, como el coraje y el amor a la patria y a la humanidad, que hasta el momento sólo eran lícitas para los varones. Ahora bien, las republicanas del Sexenio todavía no formulaban un discurso feminista porque no defendían un destino individual para la mujer separado de la familia y no ponían en entredicho las bases del orden doméstico. Por otra parte el accidentalismo político sería un factor 
explicativo de por qué en un momento de ansia democrática, como fue el Sexenio, ni siquiera las más feministas de las republicanas exigieron el sufragio. Aquella posible demanda siempre remetía al poder del confesionario sobre las mujeres y por ello se veía como prioritario darles instrucción y luchar por la laicidad. Así, las republicanas reclamaron el acceso a la enseñanza y fundaron y asistieron a escuelas laicas. En España y en otros países católicos, durante el siglo XIX, la lucha contra la hegemonía ejercida por el clero sobre la mujer y en favor de su instrucción substituyeron al combate por el sufragio femenino ${ }^{5}$.

\section{El feminismo de la Unión Obrera Balear y el Congreso Femenino Nacional}

La Unión Obrera Balear, fundada en 1881 por republicanos federales, fue la sociedad que organizó a la mayor parte de los gremios, contando con secciones en numerosos pueblos. Planteaba la redención obrera por la via del cooperativismo, la instrucción y el logro de una legislación social. La Unión Obrera Balear fue muy eficaz en la prestación de servicios a los asociados. Contaba con escuelas, una completa biblioteca, un orfeón, una banda de música, una caja de ahorros y varias cooperativas. Mientras que cubría servicios sociales y de salud mediante una casa asilo para huérfanos, asistencia sanitaria, aseguraba pensiones a sus enfermos y un Montepío para inválidos de trabajo. Todos estos servicios fueron posibles gracias a una buena administración y al apoyo de unos diez mil asociados. También fue importante la ayuda económica que le prestaron maestros de taller y algunos fabricantes republicanos. El carácter reformista de la Unión hizo que tuviera las simpatías de la burguesía modernizadora mallorquina, que la consideraba una alternativa al sector anarquista. Pero así y todo la UOB fue blanco de las amenazas de la burguesía conservadora y de la intransigencia clerical, las cuales intentaron cerrar sus escuelas, de influencia krausista, prohibir sus funciones de beneficencia laica, despedir a sus afiliados y reventar sus manifestaciones. Estas presiones seguramente fueron las que acabaron en los años 90 con la organización, ya huérfana de la protección republicana debido al desplome causado por la nueva hegemonía del maurismo.

La Unión Obrera Balear había sido fundada por antiguos republicanos federales, la mayoría encuadrados en la facción intransigente durante el Sexenio. Algunos de los dirigentes de la entidad habían sido miembros de la sociedad obrera el Auxilio Federal en los primeros setentas. La UOB contaba con una sección de mujeres, señoras se llamaban, sin especificar a que ramo laboral se adscribían. Algunas de ellas habían tomado parte en el obrerismo republicano en tiempos del Sexenio, aunque se ha de lamentar que no ha sido posible sacar de la invisibilidad a gran parte de aquellas republicanas. Tan sólo se ha podido documentar que Magdalena Bonet Fabregas, la antigua dirigente federal, miembro del Auxilio Federal en 1873, volvía a tener un papel de primer orden en la Sección de Señoras de la Unión. Otra líder relevante de la UOB, de quien se pudo hacer el seguimiento, fue Francisca Vidal Tous, una de las modistas bakuninistas que fundaron en 1870 la Virtud Social. Se ha de poner de relieve que la Unión Obrera Balear había heredado de aquellos orígenes la preocupación por la emancipación femenina.

En la Unión Obrera Balear confluyeron hombres y mujeres espiritistas y protestantes, muchos de los cuales compartirían la doble adscripción. Según se desprende del periódico Unión Obrera Balear tanto aquél movimiento obrero como el protestantismo y el espiritismo hicieron las mismas interpretaciones de los textos bíblicos ${ }^{6}$. Era una interpretación social que se identificaba con el primer cristianismo, mientras que rechazaban el exclusivismo intolerante del catolicismo y no aceptaban el papel de intermediarios de los curas por anatemizar el

\footnotetext{
${ }^{5}$ FAGOAGA, Concha La voz y el voto de las mujeres. El sufragismo en España 1877-1931, Ed. Icaria, Barcelona 1985.

${ }^{6}$ SÁNCHEZ FERRÉ, Pere "Els orígens del feminisme a Catalunya (1870-1920)" a Revista de Catalunya, núm. 45, oct. 1990, p. p. 33-49. HORTA, Gerard Cos i revolució. L'espiritisme català o les paradoxes de la modernitat, prólogo de Manuel Delgado, Edicions de 1984, Barcelona 2004.
} 
pensamiento racional y científico. También el ritual católico era criticado como la farsa, substitución de lo que tendría que ser una religión personal y consecuente con el mandamiento cristiano del amor. La masonería y el librepensamiento recogían otra parte de la disidencia social y política. Y concretando en la Unión Obrera Balear, sólo hemos documentado como masón, de entre los miembros de su junta, al vicepresidente Claudio Valls. Pero, por otra parte, sabemos que la UOB contó con el apoyo del destacado masón y republicano de Barcelona Juan Salas Antón. Fue uno de los hombres feministas y librepensadores que impartieron mítines a favor de la emancipación femenina ${ }^{7}$. En aquellos actos y campañas compartía reivindicaciones con las primeras líderes del feminismo de Cataluña: Amalia Domingo, desde el espiritismo; Ángeles López de Ayala, desde el republicanismo y Teresa Claramunt, desde el anarquismo ${ }^{8}$. Se ha de destacar que Juan Salas Antón fue un activo dirigente del cooperativismo republicano, al que confirió un carácter socializante y reformista, en la línea del que seguía la UOB. Desde Barcelona Salas Antón fue un entusiasta propagandista del Congreso Femenino Nacional que se había de celebrar en Palma.

En Barcelona residía también otro defensor de aquél congreso feminista, se trataba del menorquín Antonio Tudury y Pons, activo librepensador que había fundado en aquella ciudad numerosas escuelas laicas. En abril de 1883 Tudury visitaba Mallorca con el fin de abrir centros de enseñanza laica y con la especial misión de ayudar a organizar dicho congreso. Publicaba artículos animando a las feministas mallorquinas a seguir con aquel proyecto y las informaba de la entusiasta adhesión que había despertado en Cataluña y en el resto de España. Prueba de que las organizadoras del congreso habían buscado respaldo fuera de la isla es que una de las primeras noticias publicadas por el periódico Unión Obrera Balear sobre el congreso era que la prensa liberal española pronto comentaría el evento. Aquel periódico entre febrero y marzo de 1883 sacó a la luz escritos de solidaridad con el congreso, llegados de diferentes ciudades españolas, como la sociedad Acacia de Valencia, la cual ya había elegido a una comisión de mujeres que ayudarían en los preparativos. También publicaba que estaban llegando a la redacción muchas cartas de solidaridad de todas las ciudades españolas.

A principios de febrero Magdalena Bonet, la presidenta del futuro Congreso Femenino Nacional, pronunciaba su primer discurso en el local de la UOB, alentando a mujeres y a hombres a apoyar la iniciativa. Magdalena argumentaba que tenían que ser solamente las mujeres las que pusieran los fundamentos de su liberación y que los hombres las tenían que dejar dirigir el proceso, limitándose a ayudarlas. A finales de octubre salía la noticia de que el congreso sería presidido por la doctora catalana Martina Castells y Ballespí, la segunda médica española ${ }^{9}$. Martina provenía de una familia de tradición médica y de ideas progresistas ya que algunos de sus hermanos eran republicanos y masones. Desgraciadamente la joven ginecóloga, que había abierto consulta en Reus, no pudo ejercer durante mucho tiempo ni su profesión ni su actividad en favor de la emancipación femenina, ya que falleció súbitamente en 1884.

El semanario Unión Obrera Balear publicaba en julio de 1883 un suplemento que reproducía la circular de la Junta de Señoras, organizadora del congreso. Resulta interesantísimo seguir el discurso ideológico en que aquellas mujeres basaban la necesidad de convocar el congreso y, en última instancia, la redención femenina. La idea matriz que alimentaba la argumentación de las feministas mallorquinas era la de otorgar a la mujer el lugar moral, intelectual y material que le correspondía en la sociedad. Porque continuaba siendo la conquista del más fuerte, desde el momento en que sólo le hacía concesiones y le negaba sus derechos. El hombre continuaba autoconsiderándose poseedor en exclusiva de la inteligencia, negando a la mujer el espacio social y recluyéndola en el mundo doméstico. Las organizadoras del congreso

\footnotetext{
${ }^{7}$ SÁNCHEZ FERRÉ, Pere, La maçoneria a Catalunya 1868-1936, Ed. 62, Barcelona 1990.

${ }^{8}$ SÁNCHEZ FERRÉ, Pere, "Els orígens del feminisme a Catalunya...", op. cit.

${ }^{9}$ En realidad Martina fue la primera que ejerció la carrera ya que María Elena Maseras había acabado un poco antes pero nunca ejerció la medicina. Aquellas primeras universitarias tuvieron el doble reto de estudiar y a la vez defender a su género ante los ataques misóginos. Véase de FLECHA, Consuelo Las primeras universitarias en España 1872-1910, Ed. Narcea, Madrid 1996.
} 
acababan deshaciendo los dos argumentos que el dominio masculino argüía para marginar a la mujer: su naturaleza irracional y el peso de la costumbre. Sostenían que el congreso tendría como finalidad táctica conseguir el derecho a la educación de las mujeres, lo cual las capacitaría para abrirse camino en la vida, sin tenerse que subordinar a nadie. Seguidamente las componentes de la junta organizadora del congreso caracterizaban el proceso y la organización de éste, que sería de ámbito español aunque se invitarían a eminencias extranjeras, especialmente femeninas. El congreso no se celebraría hasta que no se hubiera establecido en todas las capitales de provincia de España una junta de mujeres de la organización. Entonces la junta que ellas integraban se disolvería para ser sustituida por una de coordinación estatal.

Pero muy pronto aquella organización feminista se vio afectada por la estrategia que seguía la Iglesia contra todo proyecto modernizador y laico en la Mallorca de entonces ${ }^{10}$. Como en otras ocasiones la campaña de desprestigio la empezó el periódico El Áncora, adalid del confesionalismo que intentaba relacionar toda iniciativa progresista con la masonería y la revolución social. El propósito era aislar el laicismo y enemistarlo hasta con los sectores más progresistas del Partido Liberal. En esta estrategia coincidía la jerarquía católica y el ascendente liberalismo, ya hegemonizado por Antonio Maura, cuyo hermano Miguel era director del periódico integrista El Áncora, puntal del maurismo. Ya que el objetivo de los liberales dinásticos durante los primeros años 80 fue debilitar al republicanismo, tildándolo de radical y absorbiendo a sus miembros más posibilistas.

La campaña de desprestigio contra las organizadoras del Congreso Femenino Nacional por parte de influyentes sectores católicos creó dificultades a la Unión Obrera Balear. En este orden de cosas, se han de relacionar los problemas que se le suscitaron a la UOB a raíz de la compra de la nueva sede con la suspensión de los preparativos del congreso, a finales del verano de 1883. Prueba de las dificultades económicas por las que pasó la sociedad obrera, consecuencia del boicot clerical, es que tuvo que suspender la publicación de su periódico durante seis meses. Cuando éste reapareció, desde la redacción se explicaban los motivos de tan larga ausencia y quedaba claro que habían perdido una parte del necesario apoyo económico. Los redactores hablaban de dificultades y de haber sido calumniados; plausiblemente se referían a las acusaciones lanzadas por El Áncora que los relacionaban con la masonería. De aquella nota aclaratoria se desprendía el temor de la UOB de no poder hacer frente a los gastos del nuevo local. Ya que comentaban que, a raíz de la campaña difamatoria contra el congreso, se habían dado de baja algunos burgueses suscriptores de acciones de su nueva sede. Quedaba claro que ante la amenaza de poner en peligro toda la potente organización de la Unión se había desistido de organizar el congreso.

Para acabar, se ha de contextualizar el Congreso Femenino Nacional, una iniciativa tan ambiciosa,- quería ser de ámbito nacional y incluso internacional,- relacionándolo con los proyectos modernizadores del progresismo y generado en la Mallorca comercial y industrial del XIX. Aquel feminismo de los primeros ochentas sería deudor, por una parte, de la praxis y del nivel de análisis alcanzados por la Virtud Social, la asociación internacionalista de modistas. Por otra parte, también sería una continuación de la presencia pública, de las publicaciones y de los mítines de las jóvenes republicanas del Sexenio Democrático.

\footnotetext{
${ }^{10}$ PEÑARRUBIA, Isabel, L'origen de la Caixa de Balears. Els projectes d'una burgesia modernitzadora, Ed. Documenta, Palma 2001. Véase especialmente los apartados "La redempció femenina" y "El maurisme es consolida i neutralitza l'oposició" p.p. 126-150 y 283-298 respectivamente.
} 